\title{
La Nueva Era Atómica y su Trascendencia Social.
}

Fn este ensayo, que cutregamos ro. mo una primicia inedita a nuest toreg, el Catedrático Titutlnt de Sociologia de nuestra ficultad, doctor Hoberto Mac I,ean $\mathrm{p}$ Eatencis analiza la trascendeneia social de la energía atr. mica que abre una nueva era ca cuyos umbrales está viviendo aetualmente la humanidal $y$ euyas perspectivas, en кug múltiples linefimientoy, esboza el autor del presente trabajo. "Letras"' lo reproduce como un aporte be nues. tra Facultad al estucíis do uno de log problemas de más palpitantr netualidad $y$ de más honda trascendencia en

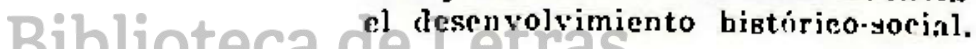

\section{"Jorge Puccinelli Converso"}

Vive la humanidad una ćpoca crucial en el ritmo de su evolución multimilenaria. Un mundo antiguo declina con el séquito de sus ideas, sus instituciones, sus normas de conducta individual y colectiva y sus temperamentos de vida. $Y$ un nuevo mundo surge con un presagio de auroras insospechadas. Está la civilización en los umbrales de una nueva era, en el pórtico de una de las más extraordinarias transformaciones de su propia fisonomia. Jamás como ahora ese cambio fué tan profundo y tan radical. Jamás llegó, como el de hoy, hasta las más hondas raíces de la sociedad, hasta las entrañas mismas de la cultura, hasta los cimientos que 
desde las profundidades del subsuelo soportan, con una firmeza que hasta ayer parecía inconmovible, toda la estructura de la convivencia humana. El átomo es el protagonista de esta transmutación universal.

Desmintiendo a su propia etimología, el átomo, por revolucionarlo todo, se ha contradicho a sí mismo. El átomo ya no es átomo. Proveniente del vocablo latino "atomus" y éste, a su vez, de dos voces griegas ( $a$ : sin; tome: división) la concepción tradicional consideró al átomo como un corpúsculo primario, infinitamente pequeño, quimica y físicamente indivisible y que constituía la hipotética unidad de la materia. Los átomos formaban, de esta suerte, unidades químicas irreductibles. Y la Química, dentro de esta concepción, estudiaba sus distintas combinaciones, la formación de las moléculas con los átomos y el equilibrio y movimientos de éstos en aquellas. Así entendido el átomo, su desintegración, la separación de sus elementos constitutivos, se consideraba antes un.delirio de la imaginación, una focura de los más audaces cultores de la utopía.

Y la utopía empezo a hacer su camino en el cerebro de los filósofos y en la acción creadora de los sabios, en un larguísimo proceso iniciado hace algunos miles de años, proceso que aún está en plena marcha, y en que se ejecutorían, una vez más, las leyes sociales de la unidad y de la continuidad de la cultura, engrandecida constantemente mientras los milenios pasan y las generaciones desaparecen. Es que, como lo afirmara Anatole France, ante la estatua de Renán, en Tréguier (1903), "la humanidad realiza lentamente, pero realiza siempre los sueños de los sabios".

Ya los filósofos de la antigüedad griega habían afirmado que la materia tenía una estructura atómica. Demó- 
crito y Leucipo fueion los primeros en decirlo. Aristóteles los impugnó y en las edades posteriores, bajo el despotismo de su influencia espiritual, que los escolísticos pretendic:-nn hacer perdurable, tales conceptos fueron combatidos y desterrados por considerárseles absurdos.

Solo en el siglo XVIII el átomo va a adquirir lentamente carta de legitimidad científica. Newton ( I642-1727), el descubridor de las leyes de la gravitación universal, definió también las que regían los movimientos de los átomos. Cien años más tarde el físico inglés Dalton ( I $776-1844$ ), investiga los pesos atómicos y actualiza, de esta suerte, !a tan combatida teoría atómica de que "todo es hecho de partículas insignificantes". Dulong y Petiot fueron los primeros en estudiar y definir el calor atómico. Desde otros ángulos de la investigación científica, sin sospechar siquiera que la posteridad eslabonaría esfuerzos que entonces parecerían tan dispares e independientes, el francés Euriquc Becquerel (1852-1908), al estudiar los Rayos X, descubrió por obra de la casualidad que el uranio emite radiaciones invisibles. Quedaba comprobada asi, en marzo de 1896 , la existencia de largadioactividad on Posteriores experimentos demostraron que en el uranio existen 39 sustancias con poder radioactivo.

Nuevas perspectivas continúan abriéndose, en la segunda mitad del siglo pasado, para revolucionar la física tradicional. El inglés Thopmson, autor de una hipótesis sobre la arquitectura atómica, encontró que los átomos estaban integrados por partículas aún más pequeñas que ellos, con cargas eléctricas negativas, corpúsculos que más tarde recibieron el nombre de "electrones". Otro compatriota suyo el físico Ruthenford (187I-1937), prosiguiendo estas investigaciones, descubrió el nuicleo del átomo - en el que luego 
encontraria Charwich cargas eléctricas neutrales- y logró transformar, por primera vez, un átomo en otro: y concibió la teoría de la estructura planetaria del átomo, que encontró plena comprobación en los experimentos del danés Bolvr. El átomo se consideró, desde entonces, como un núcleo con electrones que giran en órbita. Todavía no se sospechaba que estas transmutaciones fueran capaces de crear fuerza o energía. Pero ya se había desvanecido la teoría de la simplicidad atómica. Ya el átomo no constituía una unidad química irreductible. Resultaba formado por partículas más pequeñas, es decir por cargas eléctricas positivas ("protones"), por cargas negativas (electrones"), ambas envueltas en partículas desprovistas de toda carga eléctrica ("neutrones").

La lejana utopía de otros siglos continuaba haciéndose cada vez más tangible. Picrre y Maric Curic lograron aislar el radium y comprobaron que, con'el uranio y otros elementos, se descompone cuando se emiten los ravos radioactivos. El átomo ya no era indivisible. Había contradicho su propio nombre. Habia dejado de ser átomo. Podía, antes bien, descomponerse y producir energía. En el camino de la energía, la ciencia hizo progresos sorprendentes. El alemán Planck, también en la segunda mitad del pasado siglo, afirmó que la energía de la radiación no era continua sino que existía en pequeñas y exactas unidades, cuya medida se llamó "quanta". Marcelino Berthelot estudió los principios de la termodinámica e hizo los primeros ensayos de síntesis química. Alberto Einstein, autor de la teoría de la relativicad, dedujo en sus extraordinarias investigacio-nes, que la masa puede convertirse en energía, en forma tan completa que no đeja el menor rastro tras de sí, teoría ésta que debía ser ratificada más tarde por la bomba atómica. 
A principios de nuestro siglo $H$. Gcigcr inventó los aparatos electrónicos - salvavidas- que anuncian la presencia y el peligro de la radioactividad y sin los cuales no hubieran podido efectuarse ni los trabajos preliminares necesarios para la desintegración del átomo, ni los experimentos previos que hicieron posible la bomba atómica.

En trascendentales experimentos, al someter el átomo a los rayos X, el inglés Moseley (1887-1915), demostró que cada elemento tenía un número atómico definido y que encontraba su ubicación en la Tabla Periódica formulada por el ruso Mendelyeci' ( $1834-1907$ ) e integrada por 92 elementos conocidos, colocados de acuerdo con sus pesos atómicos.

El uranio debía protagonizar los nuevos avances. Madame Irene Joliot, tiija de los Curie, junto con la radioactivida artificial, descubrió teóricamente la fisión del uranio o sea la división del átomo. Estas experiencias las aprovecharía el italiano Fcrmi quien bombardeó el uranio con electrones, haciendo nuevos átomos artificiales radioactivos. En admirable concatenación, estudiando sobre los experimentoş de Fermi, el alemán Hahn encontró que uno de los elementos más ligeros, resultante de esos experimentos, era el "barium". Sin darse cuenta de ello había logrado la ftsión o sea la división del átomo. Fué su colaboradora la doctora Lise Meitncr, austriaca de nacimiento y actualmente ciudadana estadounidense, quien se percató de la incalculable trascendencia de la fisión y realizó por primera vez el histórico experimento de la desintegración del átomo, poniendo en libertad, de esta suerte, la energía que se contenía dentro de él. Junto con esta mujer eminente completan la unidad y continuidad cultural dos sabios americanos que aún no han llegado a los 50 años de edad: Lawrence, nacido en I9OI, inventor del "ciclotrón" o sea el "superbombardeador 


\section{$-57-$}

del átomo"; y Oppenheimer, nacido en 1904, co-director - en compañia de los dos últimos y de otros más- de los experimentos epónimos que culminaron con la fabricación de la bomba atómica.

La última guerra mundial se libró en todos los frentes de la actividad humana: en las lineas de fuego, en la vanguardia y en la retaguardia, en los campos y en las ciudades, sobre los surcos ávidos y entre el clamor de las usinas, en las escuelas y en los cuarteles, en la diplomacia $y$ en el periodismo, en la vida militar $y$ en la vida civil; en el aire, en la tierra, en el subsuelo, en el mar, en el submar. En los laboratorios científicos estuvo la última palabra. Norteamericanos, alemanes y rusos, en la febril actividad de sus gabinetes físico-químicos, procurando abrir nuevas perspectivas para la ciencia, buscaron el instrumento decisivo de la victoria.-De alli salieron, por no citar sino los más importantes avances, los aviones sin piloto, las bombas cohetes, las superfortalezas volantes, el radar.

En agosto de 1942 el presidente Roosevelt, después de consultar con el Secretario de Guerra Stimson y con el general Marshall, Jefe del Estado Mayor del Ejército, impartió una orden trascendental: ejecutar el "proyecto del Distrito de Manhatam". El Mayor General Leslie Groves fué el encargado de su realización. Muy pocos sabían lo que significaba esa denominación "camouflada". Inmediatamente se inició la construcción de establecimientos especiales en armonía con el plan a desarrollar. $Y$, tal cual se había calculado, con una aproximación de seis días, se vencieron tres años de trabajos intensísimos, llevados a cabo con el mayor secreto posible. Más de 900 contratistas y algunos millares de sub-contratistas 


\section{$-5^{8}-$}

participaron en el empeño. Fué grigantesca, como es de suponerse, la labor de coordinación de los trabajos tan múltiples realizados con una sola fé, y en la que estaba, precisamente, la ciencia y la magnitud del secreto.

El If de julio de 1945 una iremenda explosión sacudió los desiertos de Alamogordo, Nuevo México, en tierras norteamericanas. Bajo los signos del más riguroso secreto militar, nacia una nueva era para la humanidad. Poco tiempo después, el 6 y 9 de agosto respectivamente, explosiones análogas borraron del mapa las ciudades japonesas de Hiroshima y Nagrasaki y dieron muerte a más de ciento veinte mil personas ( I ). Así anunció su trágico alumbramiento la bomba atómica. Breves clías más tarde, el 14 de ese mismo mes, derrotado por ella, el Mikado pedía la paz y se rendía incondicionalmente a las armas aliadas.

Alemania estaba ya muy cerca del clescubrimiento de la bomba atómica cuando sobrevino el derrumbe nazi. Los aliados encontraron en Kiel una instalación completa destinada a producir licierible arma. Noeran solo frases de propagancla las constantes amenazas de Hitler sobre sus "armas secretas". Los lideres militares aliados -y nos referimos a la revelación contenida en la Revista de las Fuerzas Aéreas del Ejército Norteamericano, en su número correspondiente al mes de julio último- están acordes en afirmar que las Naciones

(1) Isa Asociación Médica Norteamericana de San Francisco (U.S.A.) fué informada oficialmente que las dos bombas atómicas lanzadas sobre Hiroshima $y$ Nagasaki dieron muerte a ciento veinte mil personas. El Dr. Georgiev Lcro $\because$, miembro de la misión médica que investigó los efectos de la bomba atómica, informó a la Convención Médica, reunida en San Francisco, que en Hiroshima murieron 80 mil residentes, cuarenticinco mil resultaron herirlos y ochenticineo mil más necesitaron asistencia médica inmediata; $r$ que en Nagasaki murieron cuarenta mil personas, resultando heridos veinticinco mil y cincuenta mil más con necesidad inmediata de asistencia médica. 
Unidas ganaron la guerra en Europa por un margen extraordinariamente estrecho y que muy poco faltó para que Alemania ganara la competencia científica y produjera, antes que nadie, la bomba atómica, con la que hubieran hecho desaparecer todos los puertos de invasión y hubieran reducido a Inglaterra a 10 que es ahora lagasali e Hiroshima. Afirman los expertos militares que los nazis habian dispuesto armar sus proyectiles $V-2$ con bombas atómicas; que los hechos adversos se precipitaron antes que lograran fabricar la primera de ellas; y que, por eso, tuvieron que recurrir, ya desesperadamente, al uso antieconómico de las bombas $V-2$ con explosivos ordinarios, en su frustrado empeño de contener la of ensiva aliada a cualquier costo. Los bombardeos aliados en las plantas nazis de agua-fuerte en Noruega y el sabotaje continuo de los científicos noruegos retardaron los planes germanos đel desarrollo atómico. Ese retardo fué decisivo para la victoria aliada, para la cultura y para la humanidad. Dijérase, de esta suerte, que una carrera científica, una portentosa competencia entre la capacidad creadora de los sabios aceleró el fin de la segunda contienda mundial. En esa trascendental rivalidad entre Kiel y Oakbridge se estaba gestando el curso de la historia y se jugaron los destinos de la civilización y de la humanidad. Muy otra, para desgracia suya, hubiera sido su suerte si los experimentos de los laboratorios de Kiel hubieran culminado antes que los de Oakbridge.

Cinco son las bombas atómicas que se han arrojado hasta hoy. La primera fué, en vía de ensayo, en el desierto de Alamogordo (U.S.A.). La segunda y la tercera, en Hiroshima y Nagasaki, aplastaron definitivamente el poderío del Japón. A diferencia de las tres primeras, que habían caído en tierra, la cuarta fué lanzada sobre el mar, en la la- 
gtina de Bikini, Pacifico Occidental, el $1^{2}$. de julio de 1946 , ya terminada la guerra, para estudiar sus efectos destructores en una flota tripulada por animales - cuatro mil ratas blancas, doscientos carneros enfermos, doscientos cincuenta cerdos y ciento veinte ratones con predisposición al cáncercolocada alli con ese objeto: e investigar sus consecuencias radioactivas en los organismos vivientes.

Diez mil instrumentos científicos de observación y comprobación, abundando entre ellos los que se relacionaban con la distribución de la presión del calor y de las radiaciones radioactivas en la explosión atómica, se utilizaron en tan trascendental experimentr. La última bomba, que fué submarina, se hizo estallar el 25 de ese mismo mes con el objeto de estudiar sus efectos en las unidades submarinas de guerra y sus consecuencias radioactivas en las masas de agua.

Para este experimento la bomba atómica, similar a la utilizada en la prueba anterior, se encerró en un cajón hermético de hormigón armado, pencliente de un barco y sumergido a nueve metros de la superficie del agua. Mecanismos especiales de relojeria impidieron que se produjera la explosión prematuramente. A la hora convenicla, al producirse la explosión - al decir de los testigos presenciales- pareció que la bomba lanzara todo el mar hacia el cielo. Su fantástico poder y calor convirtió la laguna de Bikini en un caldero de llamas, humo y vapor. Millones de toneladas cle agua, en impresionante ascensión alcanzó tres mil metros de altura, en medio de un cielo resplandeciente y salpicado de pequeñas nubes blancas. Luego tal vez durante veinte segundos, se mantuvo aparentemente inerte, dando la impresión de que estaba inmóvil en el aire. Después en un atronador descenso, como si un techo ciclópeo se hubiese desplomado, cayó pesa- 
damente sobre la laguna, rebalsando completamente una pequeña isla cercana a Bikini. Las conmociones supersónicas submarinas, avanzando tal vez a cinco mil piés por segundo, golpearon los buques blancos e hicieron temblar a los buques observadores, a dieciseis kilómetros distantes de la explosión. Una gigantesca nube de rocío radioactivo, de niebla y de espuma se extendió lentamente sobre la laguna de Bikini y se hizo impenetrable. Olas de siete a diez piés de altura se desplazaron hacia afuera, descle el lugar de la explosión y fueron a morir sobre los arrecifes del borde interior de la garganta coralina del atolón de Bikini, a seis kilómetros de distancia. Los barcos blanco quedaron saturados con una mortífera radioactividad, suficiente para hacerlos peligrosos para cualquier tripulación clurante un año, a menos que fueran descontaminados artificialmente.

La energía atómica no sólo interesa a los técnicos. La humanidad enterai yive ahora pendiente de ella. La desintegración del uranio una de las sustancias que contiene la bomba atómica, consiste en la ruptura de los átomos de esta sustancia, provocada por el choque de los neutrones libres. Al romperse el primer átomo de uranio, bombarcleado por un neutrón, se desintegra dejando en libertad a los neụtrones que contenía, los que, a su vez, chocan contra los átomos vecinos, produciéndose así una desintegración en cadena, en forma instantánea y violenta.

Se calcula que cada bomba atómica tiene una capacidad de destrucción equivalente a seis mil bombas explosivas corrientes. Más destructiva que la explosión misma es la acción de los rayos X y de los invisibles Alpha Beta, rayos neutrones, provenientes de la bomba atómica, que solo 
aparecen clurante el estallido atómico, pero son absorbidos por la materia sólida y provocan toda otra clase de rayos, formándose así una zona de irradiación - mortal para los organismos vivos- que el coronel Straford Warren, jefe del personal de radiación en Bikini, calculó hasta en dos millas de distancia de la bomba con un espesor de dos mil piés de altura. Los seres vivos dentro de esa zona - hombres y animales - que no perezcan de inmediato por acción de los rayos, mueren al cabo de algunas semanas por efecto de los mismos o quedan lesionados permanentemente por las quemaduras radioactivas. Así se comprobó en Hiroshima y en Nagasaki.

En estas condiciones la energía atómica es solo aplicalble a la destrucción. Pern la inteligencia creadora del hombre está ya en el camino de obtener la liberación de esa energía no con el carácter instantáneo y violento que hoy tiene, sino en forma lenta, gradual y progresiva, para utilizarla en beneficio de la humanidad.

Descle el día en que la energía atómica paralizó la maquinaria bélica y cesó los fuegos de la segunda guerra mundial, se iniciarón tos ensayos para la áplicación de esa energía en la producción pacífica de la post-gucrra. Su objetivo supremo consiste en convertir el uranio o el torio en materia prima y en utilizar como fuerza motriz para fines industriales la energía liberada en forma de calor. De esta suerte la fisión nuclear no será solo la terrible amenaza, suspendida a manera de la espada de Damocles sobre la civi.lización sino también la dócil trabajadora al servicio de la humanidad. John A. Wheeler, profesor de física en la Universidad de Princeton (New York) informa del éxito inicial de los experimentos científicos encaminados a ellos y que culminarán con la instalación de la primera planta pro- 


\section{$-63-$}

ductora de energía nuclear. Cuando ello se logre advendra el equilibrio constructivo de la era atómica que ha hecho su aparición en la historia, trayendo la paz y con ella la consolidación de la democracia, pero planteándole también una disyuntiva tremenda entre la angustia $y$ la esperanza.

La energía atómica abre, en efecto, dos posibilidades decisivas: o la destrucción iconoclasta, espiritual y materiai, de todas las formas de la convivencia humana o el progreso que acreciente, en climensiones incalculables, el bienestar humano. El dilema es fatal. En uno u otro caso se transfigurarí, en un Tabor laico, la fisonomía del orbe, en esta carrera dramática entre la técnica y la vicla. ¿ La primera va a aniquilar a la segunda? ¿Va, por el contrario, a perfeccionarla, dándole nuevos bríos y nuevas floraciones? ¿ Podrá controlar el genio del hombre la fuerza inaudita que su sabiduría ha logrado desencadenar? ¿ Será arrollado por ella o ella le servirá para abrir nuevos y portentosos horizontes en el presente y en el futuro de la historia humana?

I a oportunidad del descubrimiento científico de la desintegración del aitomo $\mathrm{y}_{\text {ac }}$ del eriolento aprovechamiento de la energía que contiene ha marcado su signo indeleble en el proceso social de nuestros días. Si el éxito de los primeios ensayos no hubiera sido, como lo fué, un triunfo de la ciencia norteamericana, sino una nueva calidad de la ciencia germánica; si los alemanes antes que los americanos hubieran logrado poseer y dominar el secreto atómico; si las . primeras bombas atómicas hubieran estrellado el apocalipsis de su maravilla cósmica, no en las islas japonesas sino en las británicas, evidentemente el mundo de hoy no estaría viviendo bajo la égida promisora de las cuatro libertades, que definiera el verbo apostólico de Franklin Délano Roosevelt sino bajo el signo trágico de la swástica, símbolo del 
"nuevo orden" que Hitler, en no pocos años de locura (olectiva, trató de imponer en el orbe.

$Y$ si el primer ensayo, en vez de realizarse en el desierto de Alamogordo, hubiera interrumpido el silencio milenario de las estepas siberianas; si las bombas atómicas en vez de tener alas norteamericanas hubieran tenido alas soviéticas; si la segunda bomba no hubiera caído sobre Hiroshima sino sobre Berlín: y si el secreto de la energía atómica fuera el privilegio de la ciencia rusa, ila paz hubiera sido la misma? :La estructura social de la post-guerra hubiera sido la que se proyecta? : No hubiéramos presenciado tal vez la sovietización integral de la cultura, de la convivencia social y de las múltiples expresiones de la vida humana?.

El presente y el futuro de la humanidad se ha forjado. pues, en esa trayectoria de los experimentos científicos que descubrieron el aprovechamiento de la energía atómica. Esa energía está ahora al scrvicio de las democracias. Es el se.creto magnífico que una de ellas posee actualmente. Pero en el ordencientífico no hay secreto duradero porque la ciencia no es ni puede ser el privilegio de un grupo o de un pueblo sino el patrimonio común de la humanidad. Y no hay, por lo mismo, tratado internacional o convención diplomática que sea eficaz para mantener un secreto científico porque el genio creador del hombre, que se manifiesta en todas las latitudes, ha de convertir en letra muerta tales disposiciones $y$ ha de romper los diques que traten de impedir la expansión de su potencialidad. Así lo acredita la experiencia histórica de todos los tiempos. Ni la invención de la pólvora, ni la creación de las armas de fuego pudieron mantenerse como el secreto privilegiado de determinados pueblos. No hay claves eficaces para la acción múltiple de la ciencia. Por eso los grandes descubrimientos científicos perte- 
necen a la humanidad entera. El avión, las bombas cohetes, el radar son de todos los países que puedan construirlos. Con la energía atómica ocurrirá lo propio. El secreto que hoy la envuelve no podrá ser duradero. Los sabios soviéticos están empeñados en descubrirlo. Y lo conseguirán seguramente en un plazo que tal vez podrá ser largo en relación con la vida de un individuo, pero que no lo serí en relación con la vidà de un pueblo.

Conscientes de su responsabilidad histórica, los hombres de ciencia que trabajaron empeñosamente en los laboratorios norteamericanos en la desintegración del átomo y que conocían sus terribles efectos destructores, le dirigieron un mensaje al Presidente Truman, por intermedio del Departamento de Guerra, pidiéndole que no utilizara la bomba atómica contra el Japón sino después de haber demostrado al mundo su poder de exterminio en cualquiera de las lejanas islas del Pacífico y de haberle mandado un ultimatum al Mikado exigiéndole la rendición incondicional y previniéndole las desastrosas consecuencias de prolongar la guerra. De esta suerte la responsabilidad hubiera caido por entero sobre el Imperio del Sol Naciente. Setenta hombres de ciencia firmaban, en nombre de la humanidad, esa petición entregada en el Departamento de Guerra de U.S.A. y sobre la que se puso cl sello de "estricto secreto militar". Hasta hoy ignoran sus autores si llegó a poder đel mandatario norteamericano. Lo cierto es que no fué escuchada.

El Mayor General Leslie Groves, que tuvo a su cargo la dirección de los trabajos de la fabricación de la bomba atómica, impugnó el punto de vista de los hombres de ciencia, en un reportaje aéreo formulado por la National Broadcasting $\mathrm{C}^{\circ}$. de New York, declarando que fué inevitable arrojar las đos bombas atómicas sobre el Japón que ya antes ha- 
bía hecho caso omiso del Ultimatum de Postdam que le enviaron las Naciones Aliadas; que seguramente hubiera menospreciado el nuevo ultimatum norteamericano que pedían los científicos; $y$ que no se hubiera rendido tan fácilmente po:que se trataba de un pueblo que luchaba por su propia existencia. Más aún. Agrega el General que, a tenor de las declaraciones verticlas por los oficiales japoneses capturados después de la rendición, el Mikado no tenía el propósito de deponer las armas después de la catástrofe de Hiroshima. Fué indispensable, por eso, arrojar la segunda bomba en $\mathrm{Na}$ gasaki para demostrarle al Imperio del Sol Naciente que los norteamericanos estaban resueltos a seguir utilizando la terrible arma hasta obtener el objetivo supremo de la victoria.

No pocos hombres de ciencia, y con ellos apreciables sectores de la opinión pública estadounidense, creen que no debe subestimarse la responsabilidad asumida ante la historia por los sombríos episodios de Hiroshima y Nagasaki. El camino ha quedado abierto. $Y$ se erizará de peligros para el mundo cuando el secreto de la desintegración atómica no sea, como lo es hasta ahora, el patrimonio exclusivo de la sabiduría norteamericana.

Un veterano de la última guerra mundial, reporteadı por The National Broadcasting $\mathrm{C}^{\circ}$. de New York, en la audición radial nocturna del 13 de agosto del año en curso, declaró enfáticamente que interpretaba el sentir cle los combatientes al expresar su rotunda disconformidad con las declaraciones del general Leslie Groves y al apoyar el punto de vista de los científicos norteamericanos. Afirmó que si hace más de un año, en el fragor de la contienda, se les hubiera preguntado a los veteranos sobre la conveniencia de lanzar la bomba atómica sobre el Japón, sin ultimatum previo, todos seguramente hubieran dado una respuesta afirmativa. 
Pero agregó que ahora las cosas han cambiado al enterarse ellos de hechos que entonces ignoraban y que, por tanto, pocos serían los que continuaban pensando lo mismo. Condenó ese veterano que los E. E. U. U. hubieran fabricado la bomba atómica sin conocimiento previo de su aliado soviético, al que solo se le informó sobre su existencia y su inmediatá utilización en la Conferencia de Postdam, días antes de que fuera lanzada sobre Hiroshima; y agregó que tal actitud explicaba las suspicacias y los recelos de los Soviets frente a los E. E. U. U. a partir de entonces. Condenó igualmente ese veterano la ostentación de la bomba atómica, hecha por los E. E. U. U. en los precisos momentos en que se celebraba en París la Conferencia de la Paz: agregó que las pruebas de Bikini constituian un alarde bélico y una advertencia que tarde o temprano obtendría respuesta: pidió que se detuviera la carrera armamentista atómica y que no se fabricara una sola bomba más de esa naturaleza. "iQue no haya más Bikinis!" terminó diciendo ese veterano cuya voz difundieron en todo el continente las radioemisoras norteamericanas.

La sociología del átomo es de incalculables proyecciones. Comprobada está la influencia decisiva de la energía atómica en la guerra. Esa energia precipitó el fin de la última contienda mundial. Su acción en la paz no será menos trascendental.

La desintegración del átomo ha producido una revolución científica. Ha sido a manera de un cataclismo para el antiguo orden en las ciencias. Han caído por tierra no pocas "verdades axiomáticas" que lo fundamentaban. Dijérase que la radioactividad ha pulverizado los fundamentos del antiguo edificio científico. El principio de la conservación 
de la materia, consagrado por Javoisier desde el siglo $\mathrm{XVIII}$, ya no es un hecho incontrovertible. La realidad atómica ha rectificado la hipótesis del padre de la Química, según la cual la suma de los pesos de los cuerpos que intervienen en una reacción es igual a la suma de los pesos de los cuerpos que resultan de la misma. Ya no existe, como antes se creyó, una barrera infranqueable entre la materia y el éter, vale decir entre la materia ponderable y la imponderable, oposición que, con carácter irreductible, consagrara la ciencia hasta fines del siglo pasado. El desquiciamiento del átomo con el estallicto de sus componentes electrónicos y la subsiguiente transformación de unos elementos en otros, han comprobado que más allá de la escala atómica la diferenciación entre materia y la energía carece de fundamento cieniifico. Los problemas trascendentales relativos a los conceptos de materia y fuerza se desarrollarán en el porvenir de manerá profundamente distinta de lo ocurrido hasta hoy. Ni las más audaces concepciones científicas de otros siglos hubieran podido sospechar la acción atómica de ahora: la masa se convierte en energialen forma tan completa que no cleja la menor huella tras de sí. He ảhí uno dè/los milagros atómicos.

De incalculable trascendencia es el aprovechamiento de la energía atómica en la Medicina. Con ella se proyecta dar temporal radioactividad a las células sanguíneas del organismo para combatir la acción de los microbios infecciosos. Así lo informaron a la Asociación Norteamericana para el Adelanto de la Ciencia, con sede en Washington, los Dres. M. Blau, H. Sinason y O. Baudisch, éste último actual Director de Investigaciones de Saratoga Springs (julio, I946). La nueva medicina atómica ampliará el campo de la radiolcgía. Las partículas radioactivas aportarán soluciones en el intrincado complejo del metabolismo humano. En los Ange- 
les (U.S.A.) se está ensayando el tratamiento de la energía atómica para combatir la enfermedad mortal de la leucemia. El Distrito Técnico de Manhattan, que tan importante papel jugó en el clescubrimiento de la bomba atómica, ha empezado a distribuir en los distintos Estados de la Unión Norte Americana, los isotopos radioactivos obtenidos en los laboritorios de Oakbridge (Tennesse) que están siendo ya empleados en trabajos de investigación científica. Acaso allí se encuentre el principio de una nueva era para la terapéutica. Estos radiostopos podrán ser utilizados contra la diabetes, leucemia, anemia, caries dentales y otras enfermedades.

Los isotopos son corrientes que al ser fisionadas en hornos atómicos se convierten en elementos radioactivos. Combinados con otros elementos, inyectados en los cuerpos humanos o vegetales y medidos por los electrónicos "geiger" para graduar su intensidad, ellos pueden descubrir los procesos vitales y estudiarlos con una exactitud sin precedentes.

No es aventurado afirmar que tal vez en la medicina atómica esté también la clave de uno de los más terribles enigmas de la medicina de todos los tiempos: la solución del problema del cáncer.

Opinión general de los peritos militares, navales y aéreos es que la bomba atómica ha alterado todos los conceptos actuales de la ciencia de la guerra y que, por ende, las guerras del futuro - si las hay- nada de común van a.tener con las que, hasta ahora, han llenado no pocos capítulos en la historia del mundo. No comparte, empero, de esta creencia casi unánime, el mayor Alexander Seversky, testigo presencial de la prueba marítima de Bikini. Admite él que "la 


\section{$-70-$}

bomba atómica es incuestionablemente el explosivo más eficiente hasta ahora inventado"; pero agrega que "simplemente hace más complicada la guerra desde el punto de vista tecnológico y, por lo tanto, mayormente costosa". Otros consideran que el mayor valor de la bomba atómica aérea está en su poder de amenaza. En Bikini hundió 3 I4,000 toneladas navales, cinco barcos de guerra e inmovilizó a siete, de los setenta buques - cuya tripulación, en caso de tenerla, hubiera perecido irremisiblemente- que fueron anclados relativamente cerca, a 70 metros de distancia el uno del otro, para experimentar el poder de la bomba en ellos. Cierto es que nunca guardan tan corta distancia las unidades navales de una flota de guerra, las que generalmente se encuentran desplazadas a dos millas aproximadas la una de la otra. Consideraciones análogas pueden plantearse en las pruebas atómicas submarinas que atacan a los barcos en su punto más vulnerable, por debajo de sur línea de flotación.

Afrontando las posibilidades bélicas del futuro, las pruebas marítimas de Pikini no prencupan mayormente a la Unión Soviética que no es como los E.E.U.U. y Gran Bretaña- una potencia maritima, ni ha construido una gran armada. Bikini podría interesar a los rusos cuando ellos dispongan de la bomba atómica para arrojarla sobre las flotas de guerra británica o estadounidense.

Tampoco podría usarse con eficacia la bomba atómica contra la infantería sobre todo en aquellas zonas ocupadas por bandos beligerantes contrarios, ya que los efectos atómicos serían los mismos para unos y otros. ¿Como salvar entonces las vidas de los soldados compatriotas si están en la misma región que los adversarios y es en esta región en la que estalla la destrucción atómica?

Convengamos, empero, que todos estos enjuiciamien- 
tos críticos empalidecen ante el recuerdo dantesco de las ciudades niponas de Hiroshima y Nagasaki. No hay ciudad en el mundo que resista el estallido de una sola bomba atómica.

La guerra no solo es de la incumbencia de los estrategas. Constituye también un amplio dominio social. Ahora la hace, la sostiene, la gana o la pierde la nación entera porque, en los años de guerra, todos los esfuerzus nacionales se coordinan hacia la consecución del objetivo supremo: la victoria. Toda la tíctica de la guerra se revoluciona con la energía atómica. Así como la pólvora revolucionó en otros siglos la estrategia bélica, desvalorizando totalmente a los castillos feudales y a las armas eficaces hasta entonces, así tambien la energía atómica, con su poder de destrucción, (explosión, calor, radioactividad), ha comprobado la absoluta ineficacia de los actuales métodos de guerra y ha planteado, con los más sombríos caracteres, la necesidad ineludible de un reajuste decisivo que for je nuevos diseños en los barcos, en las armas, en la táctica, en la dispersion de las unidades navales de combate, "en la proteccion de los combatientes y de las ciudades contra los efectos radioactivos, en el estudio de las corrientes marítimas por los que pueden difundirse rápi.damente las radiaciones hasta contaminar las aguas de todo un puerto, en la estrategia del futuro y que utilice la energía atómica en la propulsión de los acorazados, en los aviones de guerra, y en la multiplicación de las armas mucho más mortíferas aún que las que hasta hoy se conocen. Porque eil el futuro, las guerras atómicas - si las hay - no se librarán en las líneas de fuego, en las trincheras o en los campos de batalla. Su escenario serán todos los territorios de los pueblos beligerantes, los continentes enteros. $\mathrm{Y}$ se planteará a 
los paises combatientes la misma disyuntiva que afrontaron, en los albores de la humanidad, las tribus en lucha: triunfar o desaparecer. Así concibieron la guerra los primeros grupos humanos en las épocas trogloditicas. No había vencidos sobrevivientes. El grupo vencedor exterminaba totalmente al grupo vencido, en la etapa inicial de la evolución colectiva, antes que la humanidad conociera la esclavitud, proveniente también de la guerra, en una segunda etapa prehistórica. cuando los vencedores, no temiendo ya la reacción de los vencidos sobrevivientes, les respetaron la vida, pero los esclavizaron para que trabajaran en provecho de sus amos.

No habrá tampoco vencidos sobrevivientes en las futuras guerras atómicas que, donde se produzcan, multiplicarán las visiones del apncalipsis, uniendo asi, a través de las edades, en un original ricorsi, y bajo los signos del odio y de la destrucción, el principio y el fin de la humanídad; y acreditando con ello que el hombre super-civilizado del siglo $\mathrm{XX}$ conserva, en el fondo de sí mismo, iguales instintos que alentaron al hombre salvaje deda más remota prehistoria, en la era mítica en que, bajo èl soplo deb misterio creador de la naturaleza, surgió en el mundo la especie humana.

$Y$ la bomba atómica no es aún, apesar de tocio, el pináculo de la sabiduría destructora del hombre. Todavía se puede ir muchísimo más allá. Por eso el General Henry Arnold, del ejército estadounidense, afirma que es posible la fabricación de una nueva bomba atómica ante la que resul. ten insignificantes las que se arrojaron en Hiroshima, Nagasaki y Bikini; que es factible la construcción de fortalezas volantes sin piloto, capaces de cargar varias bombas atómicas; y que nada podrá entonces contener una "blitz" atómica. La fabricación de armas atómicas marcha aceleradamente. Y 
el peligro se acentúa porque no marchan con igual celeridad los empeños para someter a control internacional la energía proveniente de la fisión nuclear. De esa pavorosa visión del futuro debe surgir sinembargo la afirmación civilizadora de la conciencia internacional que elimine todas las posibilidades de la guerra. La terceta guerra mundial no debe desencarlenarse jamás. Si ella estalla escribiría, con los más sombríos caracteres, el último capítulo de la historia del hombre sobre la tierra.

Tal vez intuyó la era atómica Anatole France cuando, a principios de este siglo y en una de sus visiones del futuro, afirmó que después de muerto el último hombre "nuestro planeta continuaría rodando, llevando a través de los espacios silenciosos las cenizas de la humanidad, los poemas de Honero y los augustos restos de los mármoles griegos prendidos a sus flancos helados".

Creen algunos optimistas que la humanidad se detendrá al borde del abismo, horrorizada ante la posibilidad de una catástrofe de tal magnitud; y que, por ende, el arma atómica, lejos de estimularlas, evitará las guerras en el futuro. Difícil de predecirlo. Ya el filósofo Spéncer, sin embargo, al estudiar las perspectivas idealistas de una paz perdurable. afirmó que ese anhelo no sería el resultado de la superación moral del hombre sino mas bien de "los inventos bélicos que llegarían a ser tan terribles y destructores que la humanidad, amenazada, renunciaría a las guerras para no desaparecer en una catástrofe mundial". Tal vez la bomba atómica cumpla la previsión spenceriana. $Y$ tal vez sea un indicio de ello el empeño del organismo internacional, representante de las Naciones Unidas, para resolver la grave cuestión que plantea la elaboración y la custodia de tan te- 
rrible arma, a fin de mantener y consulidar, de esta suerte, la paz del mundo. Todavia, empero, la energía atómica no ha jronunciado su última palabra. En esa palabra decisiva - paz o guerra- está escrita la suerte de la civilización y de la humanidad.

Enjuiciando esta tremenda disyuntiva, el Presidente Truman, al recibir en julio de 1946 el título de Doctor en Derecho Honoris-Causa en la Universidad de Fordham (New York), subrayó las "nuevas y terribles responsabilidades docentes que la desintegración del átomo ha impuesto a la cultura". "La civilización - dijo entonces el mandatario- no podrá sobrevivir a una guerra atómica. Nada sino escombros quedaría en el mundo después de ella. Se habria perdido definitivamente la esperanza de conocer la más importante época en la historia de la humaniclad, una época en que se pueda dirigir la energía del átomo para el progreso de la misma y no para su destrucción. La ignorancia y sus satélites - el prejuicio, la intolerancia y la desconfianza- son las que engendran đas dictaduras y provocan las guerras. No debemos dvidarlo. Porelo mismo esperemos que la educación llegue a obliterar la ignorancia que. amenaza con producir la catástrofe. Corresponde, pues, a los planteles de enseñanza facilitar la comprensión entre los pueblos, lo que es de especial importancia para la paz". Evocó Truman, en esta oportunidad, la concepción del Presidente Roosevelt, en el sentido de que la existencia de la civilización dependía del cultivo de la ciencia de las relaciones humanas que capacita a los pueblos para vivir en armonía. "Mientras los hombres no aprendan a dominar esa ciencia - dijo Truman - la bomba atómica seguirá siendo el arma aterradora que amenaza aniquilarnos a todos. Pero existe una 
defensa contra esa bomba. Es la defensa de la tolerancia, de la comprensión. de la inteligencia y de la reflexión. Cuando lleguemos a aprender estas cosas, nos será posible demostrar que Hiroshima no fué el fin de la civilización. sino mas bien el principio de un nuevo mundo: un mundo más perfecto que el de antes".

No hay dcfensa posible contra el ataque atómico. La inteligencia creadora del hombre no siempre ha logrado inventar de inmediato las defensas contra las nuevas armas mortíferas. Los sabios confiesan su perplejidad y su impotencia para forjar los elementos defensivos ante una agresión atómica. Esta puede venir en dos formas: o el sabotaje o el ataque aéreo. No es difícil ocultar los elementos atómicos en las ciudades, en las fábricas o en los centros de producción para hacerlos estallar en cumplimiento de un plan de sabotaje que podría inmovilizar rápidamente la viđa civil de un pueblo. ¿Cómo prevenir esa acción? Un vigorosísimo control policial sobre las actividades individuales y colectivas, una labor inquisitorial en la marcháde los mercados y de las industrias, una infatigable pesquisa uequeltendría seguramente mucho de común con la Gestapo- no podría, apesar de todo, garantizar a la sociedad contra el sabotaje atómico. No hay defensa adecuada para ello.

Los hombres de ciencia, aún los más optimistas y esperanzados, tampoco vislumbran la posibilidad de una defensa contra los ataques aéreos atómicos. No existe ningún sistema de alarma para prevenirlos. Es imposible detener, desviar o destruir un avión o un transporte atómico antes de que llegue a su destino. No hay ningún medio para hacer estallar el proyectil atómico antes de que choque en el blanco. Todas las ventajas serían para el agresor. En el momento de la 
agresión el dilema no puede ser más trágico para los atacađos: si se ocultan en los refugios antiaéreos serán acorralados por la radioactividad; si salen afuera los despedazará la explosión. En ambos casos, la muerte es segura. La devastación no sería el episodio final del ataque atómico. A ella sigue la radioactividad - asesino invisible- que impediría el intento de las labores de salvamento y del socorro de la Cruz Roja. Aventurarse hacia la zona atacada, después de realizada la agresión, sería un acto suicida, por la supervivencia de la radioactividad.

No cabe, pues, defensa material posible contra el ataque atómico. Por eso, desesperanzada de encontrarla, la civilización vuelve los ojos hacia otras formas de defensa, inspiradas en los sentimientos humanos. La única defensa que el mundo de hoy puede utilizar, en previsión de tales ataques, es la del control de la encrgía atómica. Todos los empeños de las grandes potencias se concentran en la consecución de esta finalidad subrema, no exenta, a suyez, de graves dificultades en el campo de las relaciones internacionales.

El problema internacional de la energía atómica se plantea $\mathrm{y}$ debate en torno a dos principios fundamentales: el control internacional y la soberanía nacional. La diplomacia estadounidense sostiene el primer principio: los Soviets, el segundo. Es este uno de los asuntos de la post-guerra y que ha producido la más enorme grieta entre los Soviets y las democracias occidentales. Rusia no acepta de buen grado que los Estados Unidos de Norte América mantengan indefinidamente el monopolio del secreto atómico. Consideran que ese monopolio consagra una superioridad indiscu- 
tible de la gran potencia que lo detenta sobre las demás grandes potencias y entrega, en consecuencia, a un solo pais el rumbo de la historia. Las điscusiones sobre el control internacional de la energía atómica en la Sociedad de las Naciones Unidas han demostrado las posiciones discrepantes e irreductibles de Rusia y de los E.E. U.U.

El plan norteamericano para el control de la energía atómica, presentado ante el Consejo de Seguridad de las Naciones Unidas, consiste fundamentalmente en un sistema de fiscalización eficaz sobre todas las existencias de uranio, torio y sus derivados fusionables, sin los cuales no puede producirse en la actualidad la energía atómica. Un organismo especial - "Autoridad para el Desarrollo Atómico" (ADA) - con un personal integrado por expertos de muchas naciones tendría derecho para continuar explorando el subsucio, en busca de los citados minerales y se convertiría en propietaria o controladora de todos los depósitos en donde fueran encontrados, encargándose también de la extracción y refinación de los mismos y de su entrega a las fábricas para tusos pacíficos elindustriales (materiales para medicina. producción de fuerza motriz, etc). EE. UU. afirman la necesidad de limitar la producción de los explosivos atómicos en las fábricas especiales de la ADA, las que, al igual de las reservas de las "materias fisionables", serían distribuidas en distintas partes del mundo, para evitar el peligro de que se encuentren en una zona centralizada. Ios esfuerzos necesarios para llevar al uranio y al torio desde la mina a la bomba requieren tal tiempo y exigen tal naturaleza de plantas y actividades especiales que se descarta la posibilidad de que se conspire para fabricar bombas atómicas, con fines bélicos en forma oculta. 
En el Consejo de Seguridad de las Naciones Unidas existe el veto por $\epsilon l$ cual, si lo formula, cualquiera de las cinco grandes potencias puede anular cualquier acuerdo aunque fuere tomado por todas las demás restantes. Los Estados Unidos plantean la necesidad de suprimir el veto en el control de la energía atómica, a fin de que ese instrumento juridico no pueda encubrir a la nación que proyecte, con fines destructivos, el uso de tal energía. El delegado norteamericano Bernard M. Baruch, fundamentando esta ponencia, expresó elocuentemente: "I.a bomba no espera los debates. Demorar puede significar morir". Sanciones efectivas e inmediatas recaerían sobre cualquier nación que sea descubierta en posesión ilegal de una bomba atómica, del materiàl que pudiera usarse para su fabricación y cualquier fábrica o proyecto contrario al plan de control mundial de la energía atómica. Finalmente el plan estadounidense contempla la forma como este país daría a conocer los datos que posee para la fabricación de la bomba atómica en etapas graduales y lentas, conforme vaya asegurándose que funcionan eficazmente los distintos sistemas de controles que se establezcan.

Cinco peritos del Departamento de Estado fueron los encargados de elaborar el plan norteamericano y ellos lo hicieron después de afrontar la realidad y sus posibilidades. Dos minerales - el uranio y el torio- forman las materias primas para la producción de la energía atómica, tanto la que se aplica a fines pacíficos como la que se destina a la fabricación de la bomba. Cabía entonces la posibilidad y el peligro de que, en un momento dado, cualquier nación que estuviese autorizada para manipular esas materias primas con fines pacíficos, lo hiciera, a espaldas de toda autorización y sin que nadie pudiera evitarlo, con propósitos bélicos. Ningún 
pacto internacional podría controlar o evitar, de esta sue:te, la fabricación de bombas atómicas. Las naciones, dentro cle este sistema, vivirían en un ambiente internacional de perenne acechanza, recelos, sospechas recíprocas, temores y peligros.

Tampoco sería posible limitarse a castigar severamente al culpable después de haber arrojado una bomba atómica porque ello equivaldría a entregarle todas las ventajas al agresor y a no hacer nada para evitar las guerras atómicas. Tal estado constituiría un permanente factor de perturbación internacional. Lo propio ocurriría con las inspecciones internacionales. Ella no daría en la práctica ningún resultado positivo no solo por la ineficacia de tales inspecciones ante una nación dispuesta a eludirlas, sino también porque los inspectores difícilmente poseerian todos los conocimientos para dominar la técnica y correrían el riesgo de ser burlados con un simple cambio de los diseños para ocultar la verdadera finalidad de los mismos. Era necesario entonces que ese control estuvieracejercitado por los organismos científicos internacionales, tal conio se contempla en el plan norteamericano, surgido así de la realidad viviente. Hay quienes lo objetan afirmando que ese plan no garantiza definitivamente la paz ni pone fin a las guerras. Podemos replicar afirmando que es posible que la guerra subsista; pero que, en cambio, si el mundo adopta ese plan no volverán a haber más guerras atómicas.

El plan sorićtico difiere del norteamericano. Rusia no acepta la creación de un nuevo organismo o autoridad internacional para el control de la energía atómica, considerando que esa responsabilidad debe radicarse en la actual Comisión de Control de esa energía, que funciona como una Sub-Comisión del Consejo de Seguridad de la ONU. Es- 
te Consejo está integrado por once naciones. En la Sub-Comisión participa, además, el Canadí. El plan ruso pone fuera de la ley del derecho internacional la fabricación y uso del proyectil atómico y declara que, en el plazo de tres meses, a partir de la firma del tratado, deben destruirse todas las reservas existentes de bombas atómicas, lo que contrasta con el desarme gradual propuesto por los Estados Unidos de Norte América. Asimismo, imjugnando las recomendaciones estadounidenses sobre el particular, los soviéticos proclaman la necesidad de mantener irrevocables las disposiciones sobre el veto en el Consejo de Seguridad de las Naciones Unidas lo que equivaldría a impedir que se impongan sanciones a la nación que violara el régimen internacional del control atómico, si una sola de las grandes potencias las vetara. Si se mantuviera el veto, en las decisiones relacionadas con ese control, como ocurre con las demás resoluciones del Consejo de Seguridad, se convertirian en letra muerta todos los sistemas y todas las sanciones que pudieran adoptarse en el control de la energía atómica. l.os Soviets podrían tener carta blanca el día en que sus sabios descubrieran el secreto de la desintegración de átomo.

Las discrepancias entre los Estados Unidos y los Soviets sobre la diplomacia atómica son fundamentales e irreductibles. La nueva grieta entre ambos países es, con este motivo, mucho más honda que las que produjeron el caso del régimen de Franco en Esrjaña, el destino de Trieste que los Soviets querían vincular definitivamente a Yugoeslavia, el reparto de las colonias italianas conquistadas por los anglo-sajones en el nor-oriente africano o las indemnizaciones de guerra que debe pagarle a Rusia la exhausta Italia.

El General Charles De Gaulle, héroe y símbolo de la resistencia francesa en los días terribles de la invasión nazi, 
apoya, con el prestigio de su nombre, el proyecto estadounidense sobre el control de la energía atómica. Asi lo ha declarado recientemente desde su retiro de Bar-Le-Duc. Afirma que nada es ahora tan importante para el mundo como la organización de la investigación, producción y control de esa energía, en forma tal que jamás sea utilizada para la đestrucción y que, por el contrario, esté al servicio permanente del desarrollo económico-social. "No olvidemos -agregó el heroico soldado- que tenemos con la humanidad deberes que están por encima de los intereses de cualquier gobierno o nación. Si no cumplimos con ese deber, un peligro de muerte se cernirá constantemente sobre todo ser vivo".

La voz conciliadora de Francia la ha llevado, oficialmente, el sabio Federico Joliot Curie, cuyo nombre, cuyo prestigio cientifico y cuyas actuales actividades se vinculan intimamente a la energía atómica. Solicita el gobierno francés el establecimiento de una autoridad internacional cuyos poderes de control emanen y sean estipulados por la Asamblea General de la ONG: Elb Consejo de Seguridad sería el asesor técnico de ese organismo internacional que resultaria responsable ante el Consejo de todas las violaciones a las reglas internacionales y de las actividades administrativas, inherentes a sit misión controladora de la energía atómica.

"Una de las dificultades principales del problema - dijo con serena claridad Joliot Curie, en un reportaje publicado en "Le Monde" (24 de julio de 1946) - reside en que actualmente hay una sola nación que posee el arma atómica y continúa fabricándola. Más esta nación sabe que de aquí a algunos años, habrá otras que probablemente serán capaces de llegar a fabricarla. La delegación francesa desearía ver interrumpida la fabricación de las bombas atómicas lo más rápiđamente posible; y considera que la firma de un 
convenio para eliminarlas es fundamental, pero ello debe estar asociado al establecimiento de un organismo de control $y$ de administración, destinado a asegurar la aplicación del convenio y a favorecer en el mundo el empleo pacífico de la energía atómica".

La intervención conciliadora de Francia logró que la Unión Soviética aceptara la fórmula para resolver el problema de Trieste, internacionalizándolo. Algunos observadores creen que el cambio de frente de la diplomacia soviética fué, mas bien, uno de los efectos internacionales de la bomba atómica, como lo fué, según ellos, la aceptación rusa a poste:-gar por un año el debate sobre el asunto de las antiguas colonias italianas y el haber aceptado la indemnización teórica de cien millones de dólares que deberá abonarle, sabe Dios cuando, la nueva República de Italia. Difícil será, empero, que en esta oportunidad las buenas intenciones de Francia logren conjugar, en el problema del átomo, las mentalidades y sobre todo los intereses tan opuestos de los rusos y de los norteamericanos.

No ocultan su desagrado ni la prensa ni los demás instrumentos de difusión del pensamiento soviético y ello tiene especial importancia en un país "dirigido" en el que ninguna expresión se hace pública, sin la previa aprobación, expresa o tácita, de los elementos gubernamentales. El periódico "Pravda", órgano del Partido Comunista, ataca enérgicamente la política atómica estadounidense, afirmando, entre otros conceptos, que las pruebas de Bikini han minado la confianza en la seriedad y sinceridad del desarme atómico norteamericano porque ellas, antes bien, demuestran que no se trata de preparativos para destruir el arma sino, poï el contrario, perfeccionarla. La radiodifusora de Moscú, haciendo juego a esta crítica, consideró que "el experimento 
de Bikini es un acicate para la carrera armamentista con toda clase de armamentos" (julio, 1946). Y su comentarista de asuntos internacionales I. Lemin afirmó textualmente: "I a niebla de la desconfianza y la sospecha creada por lia ciiplonacia atómica, todavía está obscureciendo los cielos políticos". "Los Estados Unidos están esforzándose por preservar el secreto de la energía atómica para usarla como arma politica. Desde aquel punto de vista, no hay equivoco al decir que la prueba de Bikini ha sido un paso hacia atrás en el camino del entendimiento y aquel desarrollo científico está lejos de emplear la energía atómica para fines pacificos".

Este estado de desarmonia internacional entre las propias naciones que contribuyeron a ganar la guerra ha sido uno de los efectos inmediatos de la energía atómica. No olvidemos también que las consecuencias de la radioactividad son de orden mediato y que, no por eso, dejan de ser menos mortales. Recién, pues, ha empezado a escribirse -y no por cierto bajo buenos augurios- el capítulo atómico del derecho internacional:

El Congreso Federal de losi E.E.U.U. aprobó una ley, promulgada por el Presidente Truman, entregando el control del desarrollo de la energía atómica -que hasta entonces constituian un dominio militar- a una comisión civil.

$\mathrm{El}$ control de la energía atómica es un problema que escapa a la jurisdicción nacional y adquiere dimensiones mundiales. La ciencia, como la religión y el arte, no puede constituir el patrimonio de una sola nación. Tiene, antes bien, un carácter internacional. Cada avance científico es el resultado de la conjugación de no pocas generaciones $\mathrm{y}$, dentro de cada una de ellas, de sabios pertenecientes a muy variadas nacionalidades. La trayectoria que culminó con la desin- 
tegración del átomo ha reafirmado esta ley social sobre el internacionalismo de la ciencia. $Y^{\prime}$ así como los hombres de ciencia de no pocos países aunaron sus esfuerzos en la liberación de la energía atómica, asi también los estadistas de los pueblos que tienen en sus manos los rumbos de la historı deben colaborar ahora para que esa energía, ya liberada por acción de los sabios, lejos de ser un instrumento de exterminio, sea. antes bien, la realización mesiánica del bienestar, del progreso y de la prosperidad humanos.

Si los Estados Unidos de Norte América guardaran, avaramente, el secreto de la desintegración atómica, estimularian la rivalidad cientifica de otros paises igrualmente adelantados que, a plazo más o menos largo, llegarían también al descubrimiento de esa terrible verdad. Fácil es predecir lo que ocurriría entonces en caso de un conflicto internacional. Comprendiéndolo así los E.E.U.U. han declarado que entregarán, gradualmente, ese secreto a la humanidad, en la medida en que se establezcan y garanticen los sistemas del control atómico. La bomba atómica debe ponerse al margen de las leyes internacionales. Perosesono basta. El problema es más profundo y urge afrontarlo en toda su dimensión. Y ello se obtendrá cuando, junto con la bomba atómica y siguiendo la misma suerte que ella, se pongan también fuera de la ley los principios maquiavélicos en el manejo de los asuntos internacionales, la intransigencia de los egoísmos nacionalistas y en un ambiente de franca cooperación internacional, sobre las bases de la moral cristiana, se afirme y consolide la paz del mundo. Cuando advenga ese estado espiritual en la humani. dad, no habrá ya peligro alguno en el uso de la energía atómica.

La energía atómica, al margen de la polémica doctrinaria, plantea también una cuestión internacional de facto en 
cl Nucio Mundo. La previsión de los E.E.U.U. está considerando ya la necesidad de la defensa efectiva del Canal de Panamá contra posibles ataques atómicos y admite que, para ello, se requiere el control estricto de una zona de mil seiscientos kilómetros a la redonda, descle el canal. Geográficamente esa zona comprende descle la Florida hasta la isla Trinidlad en el Mar de las Antillas y desde Guatemala hasta las Islas Galápagos. Los peritos militares estadounidenses -nos referimos concretamente a las opiniones de los generales Willis D. Crittemberg y Hubert $R$. Harmon y al Almirante John F. Shafrots, jefes de la defensa del Canal de Panamá, en la zona del Caribe, Sexta Fuerza Aérea y Séptimo Distrito Naval- afirman que la única defensa contra las nuevas armas es interceptarlas antes de que lleguen a su destino. Ello necesita cle bases militares convenientemente apertrechadas y precisará "la estrecha colaboración de Colombia, Ecuador, el Perú, Venezuela y todas las repúblicas centro-americanas y antillanas". Ya sabemos lo que significa esa "colaboración". Los países latino-americanos la brindaron durante la guerra, con evidente sacrificio de su propia soberanía y teniendo en cuenta que solo se trataba de un esfuerzo eventual Jengaras cie fal victoria común. Terminada la guerra, no ha desaparecido el peligro de un ataque al Canal de Panamá, por lo menos en hipótesis. $Y$ en nombre de esa hipótesis lo transitorio va a convertirse en permanente, quiéranlo o no los países afectados.

Uno de los motores de la evolución social es la economía. Si el materialismo histórico no se hubiera encastillado en el exclusivismo de su tesis absorbente y se hubiera limitado a proclamar la influencia de los factores económicos en los procesos colectivos, su actitud sería inobjetable. Porque esa influencia es evidente. En el engranaje del acon- 
tecer histórico las transformaciones económicas provocan transformaciones sociales y, a su vez, cada nuevo momento de la vida colectiva engendra su propio régimen económico. Pues bien, la energía atómica, aplicada a las fuentes de la producción y a las actividades de la industria, va a producir seguramente una de las revoluciones económicas más trascendentales en la historia del mundo. Mucho más radical que la provocada en la economía por la aplicación de la fuerza motriz automotora, origen de la cultura mecánica.

La aplicación pacífica de la encrgía atómica tiene perspectivas insospechadas. En la aviación puede obtener velocidades superiores a la del sonido, en un avance de cinco mil kilómetros por hora y en aviones sin piloto, idénticos a los que, con matemática precisión, funcionaron en el experimento de Bikini. Fácil es colegir la trascendencia que ello tendrá en el comercio internacional del futuro. La energía atómica revolucionará los fundamentos técnicos de las operaciones en las turbinas de gas y podrá utilizarse como fuente propulsora para las unidades navales, para movilizar maquinarias pesađas, para producir en grandes cantidades energía eléctrica, para transformar los terrenos, el suelo y el subsuelo submarinos y acaso si las propias condiciones atmosféricas de determinadas regiones. Es innegable que la energía a.tómica tiene incalculables posibilidades como fuente de potencialidad industrial; pero no es menos cierto que las previsiones no deben ser, de inmediato, tan optimistas o ilusorias. Los técnicos calculan que la desintegración de un gramo de materia puede suministrar una energia igual a la que desarrolla la combustión completa de trescientos mil kilos de carbón. Pero no pensemos tan solo en los rendimientos. Pensemos en el costo. Y nuestro entusiasmo no estará ya al rojo vivo cuando comprobemos que la desintegración de una libra 
de uranio cuesta aproximadamente cien mil dólares. Grandes capitales se han de necesitar, por tanto, para el aprovechamiento pacífico de la energía atómica, que, en consecuencia, por lo menos en la primera etapa del mismo, ha de estar ayuntada a la acción de las empresas poderosas, al monopolio de los grandes trusts. Solo en una etapa posterior, que ojalá no esté muy lejana, podrá obtenerse tal vez, si el progreso de la ciencia lo permite, el descenso en el precio de costo, con lo que se habrá liberado a la energía atómica del monopolio capitalista. Solo entonces ella conseguirá el abaratamiento en la producción industrial, lo que implica, a su vez, la disminución de horas de trabajo humano.

Sobre estas dos bases - abaratamiento en la producción y disminución de horas de trabajo- puede organizarse una sociedad mejor que la de hoy. Aún dentro de la dialéctica marxista esta conclusión resulta aceptable. Sostiene el marxismo que la justicia social será el producto de una transformación radical en la estructura económica de la sociedad. Ni las imaginaciones más atrevidas concibieron, ni remotamente, la posibilidad de una transformación tan profunda en la economía del mundo como la que se encuentra encerrada en la energía atómica. Ella ha de acarrear, por tanto, junto con la revolución económica, un cambio insospechado antes en la configuración de la vida individual y colectiva.

I as experiencias atómicas arrojan datos elocuentes que inciden en la demografía. Informes técnicos que obran en poder del Departamento de Estado en Washington, elaborados por los peritos que estudiaron las ruinas de Hiroshima y Nagasaki, revelan que, a consecuencia de la radiación, se comprobó el aumento del índice de esterilidad entre los hombres y mujeres, así como numerosos casos de a- 
borto. Ello deberá tenerse muy en cuenta en el momento en que la energía atómica sea aplicada a las actividades fecundas y creadoras de la paz, a fin de evitar que pueda producirse, como consecuencia mediata de su uso, una descapitalización del ser humano.

No parece muy fundada la suposición de que la energía atómica desplazará en el munđo industrial a la fuerza motriz proveniente de otros elementos naturales, especialmente el carbón y el petróleo. La experiencia histórica acredita que muy pocas veces el descubrimiento de una fuente de energía puso fin a las que antes se aprovechaban. Desde la más remota antigïiedad se utilizó la cascada de agua como fuerza motriz y ningún descubrimiento posterior a ella la ha eliminado del uso del hombre. Lo propio ocurrió con la madera, utilizada como combustible desde era antiquísima. Posteriormente el hombre đescubre los secretos del carbón. Luego extrae del subsuelo el océano de petróleo que se encontraba allí escondido. Las nuevas fuentes no desplazan a las anteriores. Las complementan, Y la humanidad super-civilizada de nuestros días aprovecha, simultáneamente, de todos los elementos: caídas de agua, madera, carbón, petróleo y sus derivados, electricidad y, desde hace poco, energía atómica.

El porvenir del petróleo no está, pues, amenazado con la desintegración del átomo. Así lo ha declarado, desde la tribuna panamericana de la National Broadcasting Co. de Nueva York (agosto, I946) el Vice-Presidente de la General Electric Company, co-autor del informe oficial presentado al gobierno estadouniđense sobre la energía atómica. Así lo comprenden también las grandes empresas que explotan el petróleo. Prueba elocuente de esa comprensión es que, en los umbrales de la era atómica, la Sinclair Oil Corparation haya invertido más de noventa millones de dólares en el ensanche 
de sus laboratorios y refinerías para incrementar su producción.

Lo inevitable es que en el campo de las competencias internacionales se acentúe la lucha en un nuevo plano. Ya no solo se luchará por el petróleo. Se luchará también por la posesión y explotación de los elementos radioactivos, de las materias primas indispensables para la producción de la energía atómica. Los países que las tengan serán el campo de esa lucha como ocurrió con los que escondían el oro negro y líquido debajọ de la tierra. No es aventurado predecir, por eso, la formación de grandes trusts que monopolicen la producción y explotación de los elementos atómicos; y que se reediten, en otras tierras, los episodios que el capitalismo desarrolló en el acaparamiento del petróleo.

La bomba atómica ha producido también impactos sicológicos en el individuo y en la colectividad. Ha creado una sicología del miedo, paralizador sentimiento de impotencia, ignorancia e inseg aridad general. LanAseciación de Cientificos de los E.E.U.U. a petición de la Federación de Científicos Norte Americanos, estudió este fenómeno que podía convertirse en un agente destructor y lo atribuyó al énfasis puesto en la difusión de las noticias sobre el poder exterminador de la bomba. La sicología del miedo tiene lo que se llama "su pensamiento escapista", en el intento de hallar consuelo en las afirmaciones que hacen dudosas autoridades sobre el limitado poder destructor de la bomba, en la esperanza de que pronto se hallará una defensa contra ella o de que los E.E.U.U. mantendrán por mucho tiempo el secreto de su manufactura. El miedo es susceptible de tener desviaciones 
extremas: ver por doquiera amenazas contra la seguridad colectiva, almácigo del "complejo del espionaje" que puede llegar hasta la supresión de la libertad de palabra. Sostienen los sicólogos que existe una evasión legítima frente al miedo atómico: poner más énfasis en propagar los posibles beneficios de la energía atómica que en su misión de exterminio. También otrora se tuvo miedo a la electricidad cuando, a través del rayo, solo se conocían sus manifestaciones destructoras.

El temor, y junto con él la desconfianza, han de subsistir mientras las naciones no se hayan puesto de acuerdo sobre el futuro de la energía atómica. Temores y desconfianzas de esta índole son los que esterilizan, en gran parte, los esfuerzos de los estadistas para asegurar la paz.

La nueva faz del átomo se refleja también, inevitablemente, en las teorías sociológicas que, descle muy distintos ángulos de enjuiciamiento, aspiran a interpretar el proceso social. Entre ellas figura la teoría energética que hace de la energia el epifoco de la evolución colectiva; que considera a la vida en general -incluyendo, por tanto, en ella a la vida social - como un fenómeno de transformación de energía; que afirma, con Nicolai y Ostwald, entre otros, que todo acontecimiento histórico-social (nación, estado, cultura, comercio, industrias, lenguaje, producción, artes, ciencias, etc.) es, un último análisis, una transformación de la energía bruta en energía útil; y que la misión fundamental del hombre y de la sociedad es la de ser a manera de dinamos transformadores de esa energía. Cuando la energía en potencia se activiza es susceptible de adoptar distintas orientaciones produciéndose entonces, según sean ellas, los fenóme- 
nos estéticos, políticos, religiosos, intelectuales y morales. No necesitamos de mayor énfasis dialéctico para comprobar el invalorable refuerzo que, con la desintegración del átomo, han recibido las teorías energéticas de la interpretación social. La energía es ahora - como ellas lo proclamabanla que está transformando a la civilización. El nuevo mundo que está surgiendo lleva el sello indeleble de la energía atómica. El energetismo social revitaliza su contenido, refresca sus laureles, readquiere nuevo auge y se coloca en la avanzada entre las escuelas de interpretación sociológica.

Las especulaciones en torno a la influencia atómica en la vida del hombre tienen un dominio extensísimo. En uno de sus extremos están quienes intuyen la posibilidad de usar la energía atómica como fuente de propulsión en los aviones-cohetes que podrían fabricarse para los viajes de ida y regreso a la Luna, en razón de que esa energía puede hacer un millón de veces más grande la potencialidad del combustible, comparándolo con los que el hombre" posee actualmente. En el extremo opuesto están los modistos de San Francisco (U.S.A.) que, en julio de 1946, lanzaron al mercado de la frivolidad los "sombreros atómicos", inspirados en la explosión de Bikini y descritos como de "terciopelo de color de llamarada encegadora, que sirve de base a un arco iris que estalla hacia arriba y hacia afuera en un despliegue de fuegos de artificio, todo ello coronado por una nube azul formada por cuatro plumas de avestruz y por una formación de hongos, integrada por otras cuatro plumas de la misma calidad y de color blanco ahumado". La utopía y la frivolidad resultan así los extremos opuestos de las especula- 
ciones atómicas. Tal vez los extremos, por ser tales, sean condenables. Pero entre ellos, en el espacio intermedio, la ciencia trabaja infatigablemente.

América, más de una vez, ha marcado, con vigorosos acentos, el avance de la cultura y la dirección de la historia. En la era precolombina forjó, tanto en el norte como en el sur, en los aztecas como en los peruanos, la maravilla de culturas esplendorosas. Siglos más tarde, fué el refugio y baluarte de la libertad de conciencia, perseguida en la vieja Europa. Con Benjamín Franklin - nuevo Prometeo- le arrebató a los cielos el misterio del rayo. En el siglo XVIII América le da al mundo el ejemplo de su estructura democrática, consagrada en la gesta epónima que culmina el 4 de julio de 1776 . Trece años más tarde, el espíritu norteamericano inspira la Revolución Francesa. América decide la victoria en la penúltima contienda mundial y libra entonces a la civilización de la hegemonia imperialista de las grandes potencias de la Európa CentraheMarcando ouna vez más, la ruta del mundo, cuando la humanidad contemplaba, horrorizada, los avances del "nuevo orden", opresor de todas las libertades, de ese régimen que consagraba la superioridad de unos hombres sobre otros, tan solo por el color de su piel, la forma de su cráneo o los componentes químicos de su sangre; y que negaba los derechos individuales, familiares y sociales supeditáridolos a la acción expansiva del Estado despótico; la América volvió a constituir el más firme de los baluartes y la más promisora de las garantías en el naufragio de la civilización. También esta vez el mundo le debe a la América su salvación. Y, junto con ella, el portento de 


\section{$-93-$}

la energía atómica que abre una nueva era en el desenvolvimiento de la historia universal. El átomo protagonista de la más extraordinaria transformación histórica, resulta asi el punto de apoyo que pedía el genio griego para mover el mundo.

El meridiano del hombre y de Dios pasa nuevamente ahora por América. Y pasa por América para bien de la humanidad.

Roberto Mac-Lean y Estenós. 